Results of applying a non-evaporative mitigation technique to laser-initiated surface damage on fused-silica

J. J. Adams, M. Bolourchi, J. D. Bude, G. M. Guss, M. J. Matthews, M. C. Nostrand

November 4, 2010

SPIE Laser Damage Conference Boulder, CO, United States

September 26, 2010 through September 29, 2010 
This document was prepared as an account of work sponsored by an agency of the United States government. Neither the United States government nor Lawrence Livermore National Security, LLC, nor any of their employees makes any warranty, expressed or implied, or assumes any legal liability or responsibility for the accuracy, completeness, or usefulness of any information, apparatus, product, or process disclosed, or represents that its use would not infringe privately owned rights. Reference herein to any specific commercial product, process, or service by trade name, trademark, manufacturer, or otherwise does not necessarily constitute or imply its endorsement, recommendation, or favoring by the United States government or Lawrence Livermore National Security, LLC. The views and opinions of authors expressed herein do not necessarily state or reflect those of the United States government or Lawrence Livermore National Security, LLC, and shall not be used for advertising or product endorsement purposes. 


\title{
Results of applying a non-evaporative mitigation technique to laser- initiated surface damage on fused-silica
}

\author{
J. J. Adams*, M. Bolourchi, J. D. Bude, G. M. Guss, M. J. Matthews, M. C. Nostrand \\ Lawrence Livermore National Laboratory \\ 7000 East Avenue, L-592 \\ Livermore, CA 94550
}

\begin{abstract}
We present results from a study to determine an acceptable $\mathrm{CO}_{2}$ laser-based non-evaporative mitigation protocol for use on surface damage sites in fused-silica optics. A promising protocol is identified and evaluated on a set of surface damage sites created under ICF-type laser conditions. Mitigation protocol acceptability criteria for damage re-initiation and growth, downstream intensification, and residual stress are discussed. In previous work [1], we found that a power ramp at the end of the protocol effectively minimizes the residual stress $(<25 \mathrm{MPa})$ left in the substrate. However, the biggest difficulty in determining an acceptable protocol was balancing between low re-initiation and problematic downstream intensification. Typical growing surface damage sites mitigated with a candidate $\mathrm{CO}_{2}$ laser-based mitigation protocol all survived $351 \mathrm{~nm}, 5 \mathrm{~ns}$ damage testing to fluences $>12.5 \mathrm{~J} / \mathrm{cm}^{2}$. The downstream intensification arising from the mitigated sites is evaluated, and all but one of the sites has $100 \%$ passing downstream damage expectation values. We demonstrate, for the first time, a successful non-evaporative $10.6 \mu \mathrm{m} \mathrm{CO}_{2}$ laser mitigation protocol applicable to fused-silica optics used on fusion-class lasers like the National Ignition Facility (NIF).
\end{abstract}

Keywords: Fused-silica, $\mathrm{SiO}_{2}$, surface damage, damage mitigation, $\mathrm{CO}_{2}$ laser mitigation, $\mathrm{CO}_{2}$ lasers, downstream intensification, residual stress

\section{INTRODUCTION}

Efficient operation of large aperture, multi-kilo-joule UV laser systems involves management of damage on the surfaces of the UV optics [2]. Management of this surface damage primarily involves controlling the exponential growth these sites will exhibit upon continued illumination [3]. One attractive technique to control or mitigate exponential growth of surface damage sites is via treatment with a $\mathrm{CO}_{2}$ laser [4-8]. LLNL is currently pursuing two $\mathrm{CO}_{2}$ laser-based mitigation approaches, evaporative and non-evaporative. Figure 1 illustrates the basic setup and effect on a damage site of the two approaches. The non-evaporative approach has the advantage of minimal surface perturbation or material removal, no re-deposited debris in or around the damage site, and lends itself to a simple system setup. The evaporative approach, on the other hand, offers control of the final shape of the mitigated site and it can be applied to typically larger sites with deeper cracks. In this report we discuss and demonstrate a successful non-evaporative technique (protocol).

For a mitigation protocol to be acceptable, it must satisfy three basic acceptability requirements. First, the protocol must prevent the re-initiation and/or growth of a damage site upon subsequent exposure to UV laser pulses. We require that mitigated damage sites survive testing at $3 \omega, 5 \mathrm{~ns}$ to $>12.5 \mathrm{~J} / \mathrm{cm}^{2}$ with a $<3 \%$ re-initiation rate. Second, the level of residual stress in the substrate left by the protocol must be low enough that nearby features (i.e. flaws and/or cracks) in the surface will not subsequently induce fracture. Third, the mitigated site must exhibit a final physical shape that will not cause unacceptable downstream intensification when a UV laser beam passes through it.

\footnotetext{
* Correspondence: 925 422-4663, adams29@1lnl.gov
} 


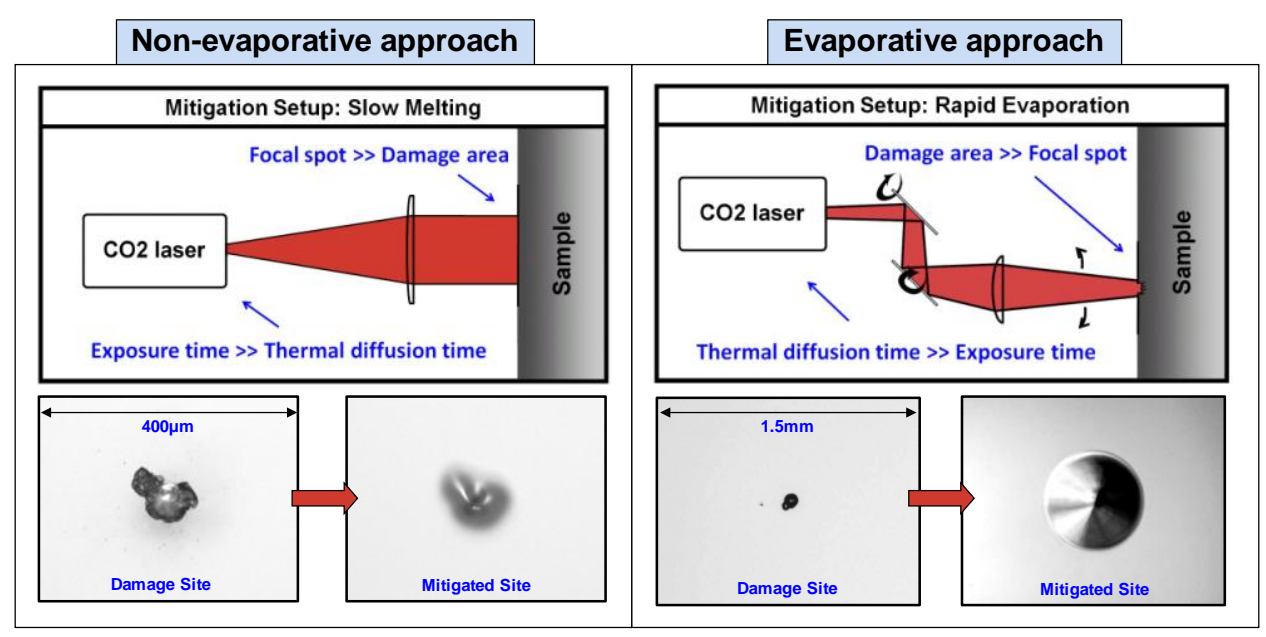

Figure 1: Illustrative comparison between evaporative and non-evaporative $\mathrm{CO}_{2}$ laser-based mitigation techniques. Note the melted appearance of mitigated site in the non-evaporative case as compared to the complete removal of the site in the evaporative case.

\section{RESULTS AND DISCUSSION}

\section{1 $\mathrm{CO}_{2}$ Laser Mitigation Setup}

A simple setup utilizing a $\mathrm{CO}_{2}$ laser was used to perform the mitigation. A schematic of the mitigation setup is shown in Figure 2. The laser utilized is a quasi-CW Synrad Firestar v20 operating at a wavelength of $10.6 \mu \mathrm{m}$. The beam was allowed to free propagate to a $\mathrm{ZnSe}$ aspherical lens where it was weakly focused through the sample plane. The spatial profile of the beam at the sample plane was Gaussian. A computer system interfaced with the $\mathrm{CO}_{2}$ laser controlled the exposure parameters during the mitigation.

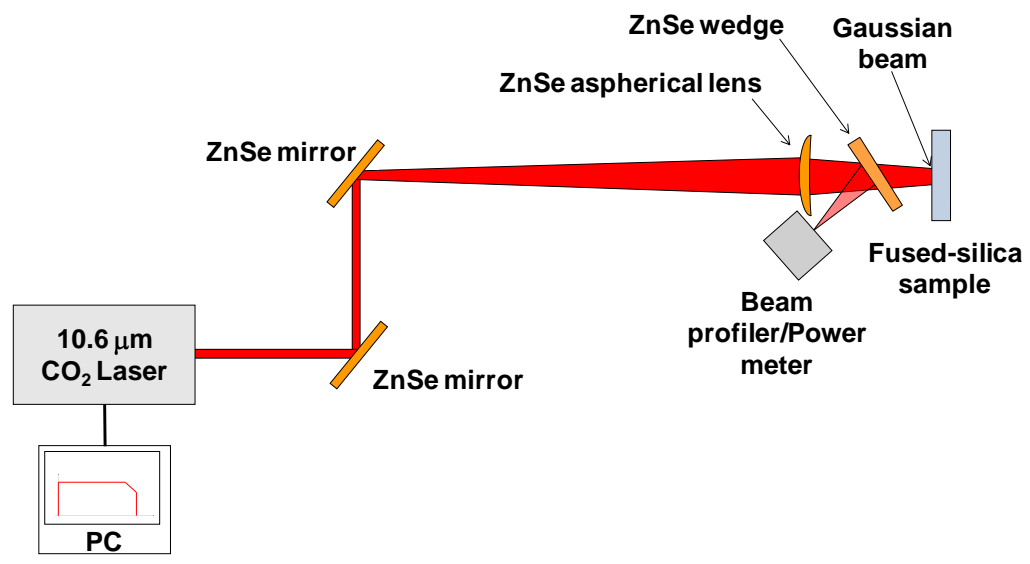

Figure 2: Schematic of the $\mathrm{CO}_{2}$ laser mitigation setup.

Growing surface damage sites were prepared on the output surface of an uncoated $50.8 \mathrm{~mm}$ diameter, $10 \mathrm{~mm}$ thick Corning 7980 fused-silica round. The sample was etched and cleaned prior to initiation. A 58 site pattern was initiated on the output surface of the sample using single pulses from a Nd:YAG laser operating at $355 \mathrm{~nm}, 7 \mathrm{~ns}$ with a 1/e ${ }^{2}$ beam diameter of $\sim 500 \mathrm{um}$. This created sites with an average site diameter of $\mathrm{D}_{\text {avg }}=70 \mu \mathrm{m}$ and a maximum site diameter of 
$\mathrm{D}_{\max }=110 \mu \mathrm{m}$. The initiated sites were then subjected to "growth" shots at $351 \mathrm{~nm}(3 \omega), 5 \mathrm{~ns}$ in LLNL's Optical Sciences Laser facility (OSL) [9] to ensure that every site was actually exhibiting growth. Only 33 out of the 58 sites initiated on the sample were single, isolated sites. Figure 3 shows an example of one of the growing sites on the sample before and after mitigation.

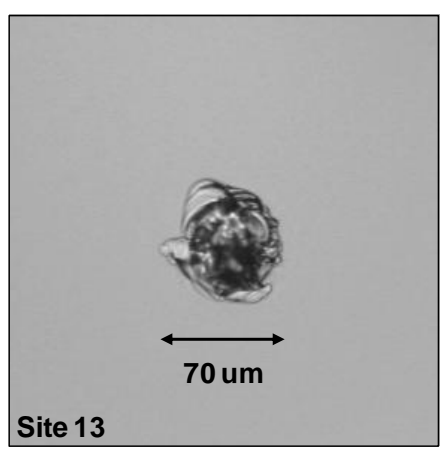

a.)

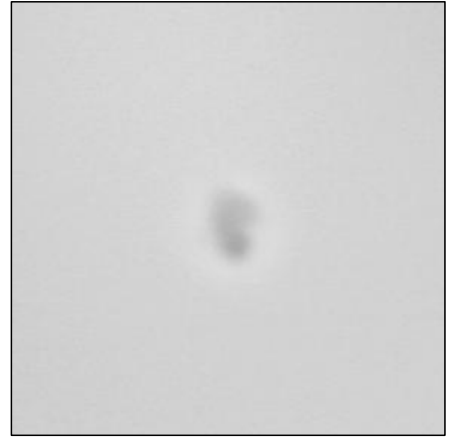

b.)

Figure 3: Micrographs of one of the growing sites on the sample: a.) Before $\mathrm{CO}_{2}$ laser mitigation and b.) $\mathrm{After}^{\mathrm{CO}_{2}}$ laser mitigation.

\subsection{Power and Exposure Time}

In general, the protocol consists of a constant $\mathrm{CO}_{2}$ laser exposure followed by a ramp down. Figure 4 shows the general power-time profile used in this study. We found that as $\mathrm{P} 1$ and/or $\mathrm{t} 1$ are increased, the re-initiation rate goes to zero; however, the downstream intensification quickly becomes problematic. Therefore, the biggest difficulty we faced in determining an acceptable protocol was balancing between low re-initiation and problematic downstream intensification. We succeeded in identifying a particular power and exposure time (P1 and t1) combination that balances these two effects.

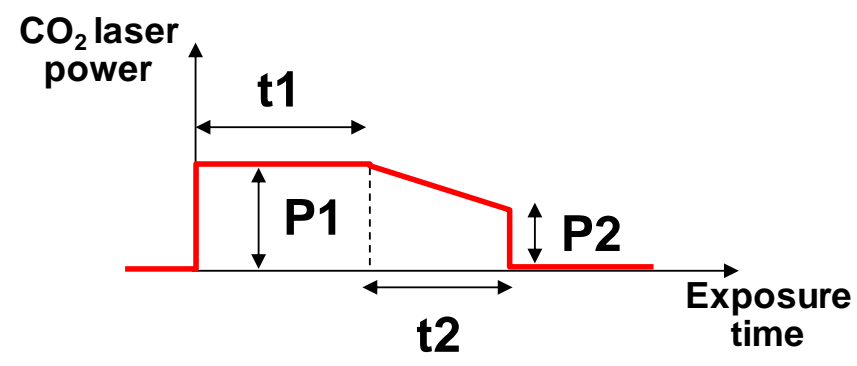

Figure 4: General $\mathrm{CO}_{2}$ laser power-exposure time profile used to mitigate the surface damage sites.

\subsection{Residual Stress}

Residual stress in and around the mitigated damage site can cause catastrophic fracture of nearby surface flaws or initiations. In previous work [1], we identified a power ramp that suitably minimizes the residual stress ( $<25 \mathrm{MPa})$ left in the substrate. The "ramp" (P2 and t2 in Figure 4) chosen efficiently minimizes the residual stress through a linear decrease in power to a temperature just below the glass transition temperature, maximizing the relaxation of the glass, followed by an immediate turn-off. 


\subsection{Damage Testing at $3 \omega, 5 \mathrm{~ns}$}

Damage tests of the mitigated sites (58) were conducted in OSL to evaluate their re-initiation probability. The damage testing was performed at $3 \omega$ with 5 ns flat-in-time temporal pulses. The samples were held at vacuum and subjected to $3 \omega$ shots at a rate of about one per hour. The sample was tested with the mitigated sites on the output surface. Figure 5 summarizes the results of the $3 \omega$ damage tests. As can be seen, no damage was observed up to an average fluence of $13.4 \mathrm{~J} / \mathrm{cm}^{2}$.

\begin{tabular}{|c|c|c|c|}
\hline $\begin{array}{c}\text { Target shot } \\
\text { fluence } \\
\left(\mathrm{J} / \mathrm{cm}^{2}\right)\end{array}$ & $\begin{array}{c}\text { Actual shot } \\
\text { fluence } \\
\left(\mathrm{J} / \mathrm{cm}^{2}\right)\end{array}$ & $\begin{array}{c}\text { Contrast \% } \\
(\text { sigma/Favg })\end{array}$ & Comments \\
\hline 8 & 8.4 & 18 & No Damage \\
\hline 10 & 10.0 & 18 & No Damage \\
\hline 12 & 12.5 & 16 & No Damage \\
\hline $13+$ & 12.3 & 16 & No Damage \\
\hline $13+$ & 13.4 & 16 & No Damage \\
\hline
\end{tabular}

Figure 5: Results of the $3 \omega$ damage testing of the mitigated sites. No damage of the mitigated sites was observed.

\subsection{Downstream Intensification}

The downstream intensification from the mitigated sites was evaluated using a LLNL built modulation measurement system. Diffraction patterns at discrete distances downstream from each of the mitigated sites were measured and the total expected number of initiations were calculated for each diffraction image [10]. The total expected number of initiations, $\langle\mathrm{N}\rangle$, per image, assuming a background fluence of $8 \mathrm{~J} / \mathrm{cm}^{2}$, was found by

$$
<N>=\sum \rho(\phi=\text { pixel fluence })(\text { pixel area })
$$

where $\rho(\phi)$ is the surface initiation number density probability as a function of fluence evaluated at a given pixel and the sum is over all the pixels in the image. The calculated total expected number of damage sites at each downstream distance (each image) were compared to a requirement of $<0.1$ initiations as shown in Figure 6.

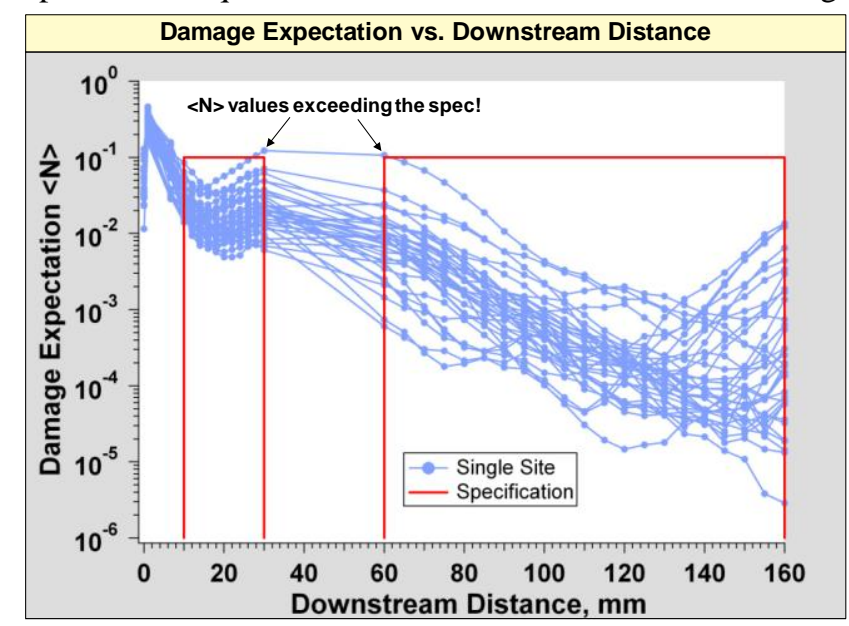

Figure 6: Calculated damage expectation values vs. downstream distance for the 33 single, isolated sites on the sample. Only one site has values that exceed the specification. 
All but one of the mitigated single, isolated sites has $100 \%$ passing damage expectation values. The one failure in this set of sites implies a $<0.3 \%$ downstream initiation probability. Subsequently, we have mitigated and damage tested 125 more sites and observed no damage re-initiation or downstream damage expectation values $>0.1$.

\section{SUMMARY}

A promising non-evaporative $\mathrm{CO}_{2}$ laser mitigation protocol was identified and evaluated on a set of NIF-like prepared surface damage sites. In general, the protocol consists of a constant $\mathrm{CO}_{2}$ laser exposure followed by a ramp down. The "ramp" profile chosen efficiently minimizes the residual stress. The mitigated surface damage sites were tested at $3 \omega$ to fluences $>12.5 \mathrm{~J} / \mathrm{cm}^{2}, 5 \mathrm{~ns}$ with no damage or re-initiation observed. The mitigated sites' downstream intensification was evaluated using a LLNL built modulation measurement system. Diffraction patterns at discrete distances downstream from the mitigated sites were measured, and the total expected number of initiations were calculated using the relation between surface damage initiation number density and fluence $(\rho(\phi))$. All but one of the mitigated sites passed the downstream damage expectation specification. The one failure implies a $<0.3 \%$ initiation probability. We have demonstrated, for the first time, a successful non-evaporative $10.6 \mu \mathrm{m} \mathrm{CO}_{2}$ laser mitigation protocol for use on fused-silica optics, such as those used in the National Ignition Facility, with surface damage sites $\leq 110 \mu \mathrm{m}$ in diameter.

\section{ACKNOWLEDGEMENTS}

The authors wish to thank Gene Donohue, Ron Luthi, Marcus Monticelli, Mary Norton, John Prior, Rusty Steele, Jim Vickers, Paul Wegner, Tim Weiland, Pam Whitman, and Steven Yang, all with LLNL, for assistance with the experiments and many helpful discussions. This work performed under the auspices of the U.S. Department of Energy by Lawrence Livermore National Laboratory under Contract DE-AC52-07NA27344. UCRL-PROC-236318

\section{REFERENCES}

[1] M. J. Matthews, J. S. Stolken, R. M. Vignes, M. A. Norton, S. Yang, J. D. Cooke, G. M. Guss, J. J. Adams, "Residual stress and damage-induced critical fracture on $\mathrm{CO}_{2}$ laser treated fused silica," Proc. SPIE Int. Soc. Opt. Eng. 7504, 750410-1 (2005).

[2] L. W. Hrubesh, M. A. Norton, W. A. Molander, E. E. Donohue, S. M. Maricle, B. Penetrante, R. M. Brusasco, W. Grundler, J. A. Butler, J. Carr, R. Hill, L. J. Summers, M. D. Feit, A. M. Rubenchik, M. H. Key, P. J. Wegner, A. K. Burnham, L. A. Hackel, and M. R. Kozlowski, "Methods for mitigating surface damage growth in NIF final optics," Proc. SPIE Int. Soc. Opt. Eng. 4679, 23 (2002).

[3] M. A. Norton, E. E. Donohue, M. D. Feit, R. P. Hackel, W. G. Hollingsworth, A. M. Rubenchik, M. L. Spaeth, "Growth of laser damage in fused $\mathrm{SiO} 2$ under multiple wavelength irradiation," Proc. SPIE Int. Soc. Opt. Eng. 5991, 8 (2005).

[4] P. Temple, H. Lowdermilk, D. Milan, "Carbon-dioxide laser polishing of fused-silica surfaces for increased laser-damage resistance at 1064 nm," Applied Optics, 21, 3249 (1982).

[5] R. M. Brusasco, B. Penetrante, J. A. Butler, L. W. Hrubesh, "Localized $\mathrm{CO}_{2}$-laser treatment for mitigation of 351-nm damage growth in fused silica,” Proc. SPIE Int. Soc. Opt. Eng. 4679, 40 (2002).

[6] R. R. Prasad, J. R. Bruere, J. Halpin, P. Lucero, S. Mills, M. Bernacil, R. P. Hackel, "Design of a production process to enhance optical performance of 3omega optics,” Proc. SPIE Int. Soc. Opt. Eng. 5273, 296 (2004).

[7] I. L. Bass, V. G. Draggoo, G. M. Guss, R. P. Hackel, M. A. Norton, "Mitigation of laser damage growth in fused silica NIF optics with a galvanometer scanned $\mathrm{CO}_{2}$ laser," Proc. SPIE Int. Soc. Opt. Eng. 6261, 62612A (2006).

[8] G. M. Guss, I. L. Bass, V. G. Draggoo, R. P. Hackel, S. A. Payne, M. Lancaster, P. Mak, "Mitigation of growth of laser initiated surface damage in fused silica using a 4.6um wavelength laser," Proc. SPIE Int. Soc. Opt. Eng. 6403, 64030M-1 (2007).

[9] M. Runkel, J. Bruere, W. Sell, T. Weiland, D. Milam, D. Hahn, M. Nostrand, "Effects of pulse duration on bulk laser damage in 350-nm raster scanned DKDP, "Proc. SPIE Int. Soc. Opt. Eng. 4932, 405 (2003). 
[10] M. J. Matthews, I. L. Bass, G. M. Guss, C. C. Widmayer, F. L. Ravizza, "Downstream intensification effects associated with $\mathrm{CO}_{2}$ laser mitigation of fused silica," Proc. SPIE Int. Soc. Opt. Eng. 6720, 67200A-1 (2008). 